\title{
Correction: Keshavmurthy, S., et al. Coral Reef Resilience in Taiwan: Lessons from Long-Term Ecological Research on the Coral Reefs of Kenting National Park (Taiwan). Journal of Marine Science and Engineering 2019, 7, 338
}

\author{
Shashank Keshavmurthy ${ }^{1,+}{ }^{1}$, Chao-Yang Kuo ${ }^{1,+} \oplus$, Ya-Yi Huang ${ }^{1}$, \\ Rodrigo Carballo-Bolaños ${ }^{1,2,3}$, Pei-Jei Meng ${ }^{4,5, *}$, Jih-Terng Wang ${ }^{6, *}$ and \\ Chaolun Allen Chen 1,2,3,7,8,* \\ 1 Biodiversity Research Center, Academia Sinica, Taipei 11529, Taiwan; coralresearchtaiwan@gmail.com (S.K.); \\ cykuo.tw@gmail.com (C.-Y.K.); lecy.yhuang@gmail.com (Y.-Y.H.); rodragoncar@gmail.com (R.C.-B.) \\ 2 Biodiversity Program, Taiwan International Graduate Program, Academia Sinica, Taipei 11529, Taiwan \\ Department of Life Science, National Taiwan Normal University, Taipei 10610, Taiwan \\ National Museum of Marine Biology/Aquarium, Pintung 94450, Taiwan \\ Insititute of Marine Biodiversity and Evolution, National Dong-Hua University, Hualien 97447, Taiwan \\ Department of Biotechnology, Tajen University, Pingtung 90741, Taiwan \\ Institute of Oceanography, National Taiwan University, Taipei 10617, Taiwan \\ Department of Life Science, Tunghai University, Taichung 40704, Taiwan \\ * Correspondence: pjmeng@nmmba.gov.tw (P.-J.M.); jtwtaiwan@gmail.com (J.-T.W.); \\ cac@gate.sinica.edu.tw (C.A.C.) \\ + These two authors contributed equally to the work described.
}

Received: 4 August 2020; Accepted: 15 September 2020; Published: 26 November 2020

The authors are sorry for errors in their paper [1], which will not affect the interpretation or final results, but will lead to confusion. Consequently the authors wish to make the following corrections to the paper:

Change in Main Body Paragraphs

> "Sianjiaowan" and "Siangjiao Bay" to be replaced with "Siangjiaowan". "Jialuoshui" replaced with "Jialeshuei", "Lidashih" replaced with "Leidashih", "Longken" replaced with "Longkeng", "Dingnaisha" replaced with "Dingbaisha", SIW replaced with SJW; exchange the citation of "Figure 2" with "Figure 3", "Figure 5c" replaced with "Figure 5e", Figure 6" replaced with "Figure 7", replace "Figures 7 and 8 " with "Figures 8 and 9", replace "Figure 7" with "Figure 8".

> Change the citation of "Table 2" to "Table 3", Table 3" to "Table 4, "Table 4" to "Table 2".

$>$ Insert "in Taioshi" between [84] and Condylactis sp.

Change in Figures/Tables

$>$ Replace Figure 2: 


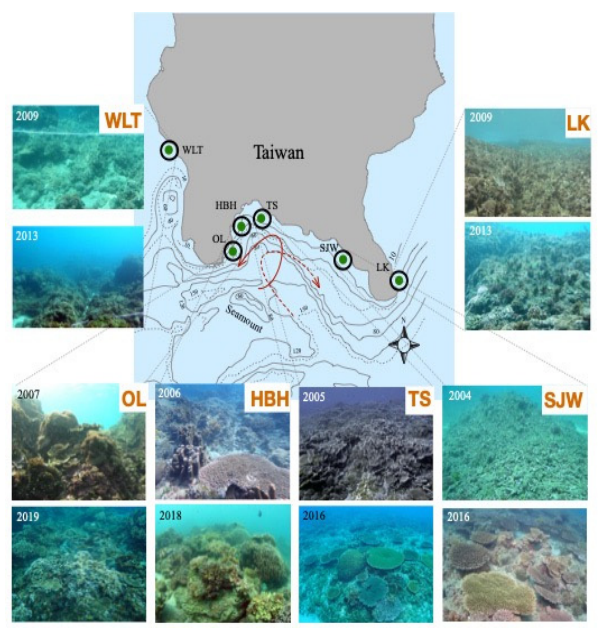

With new Figure 2 below:

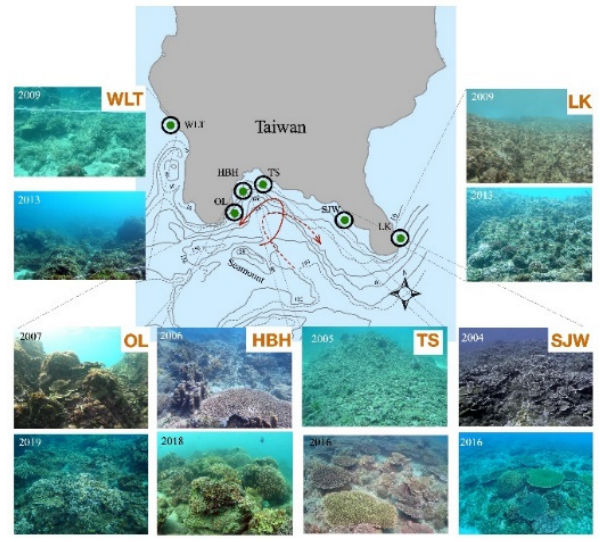

$>$ Due to mislabeling, replace Figure 5:
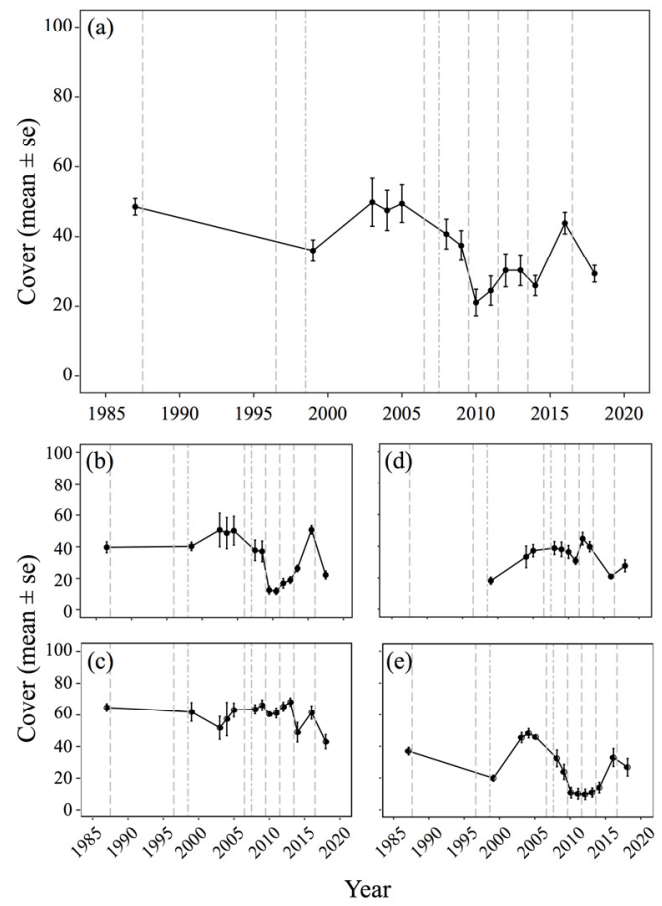
With new Figure 5:
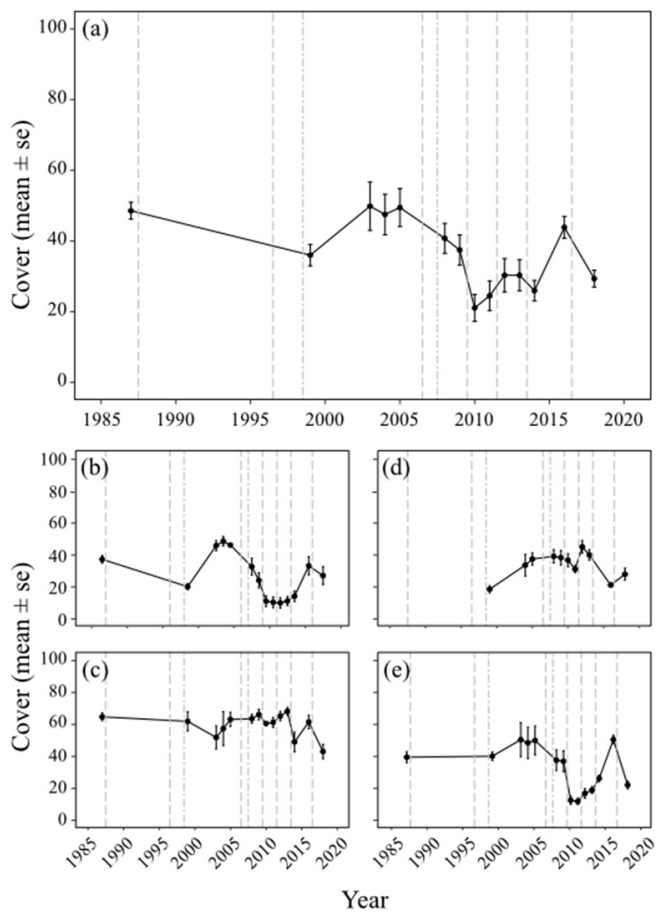

$>$ Due to the wrong pie chart, replace Figure 9:

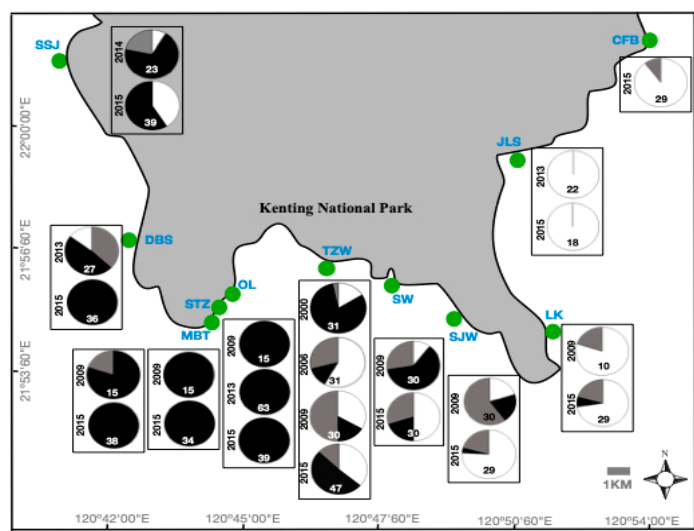

With new Figure 9 below:

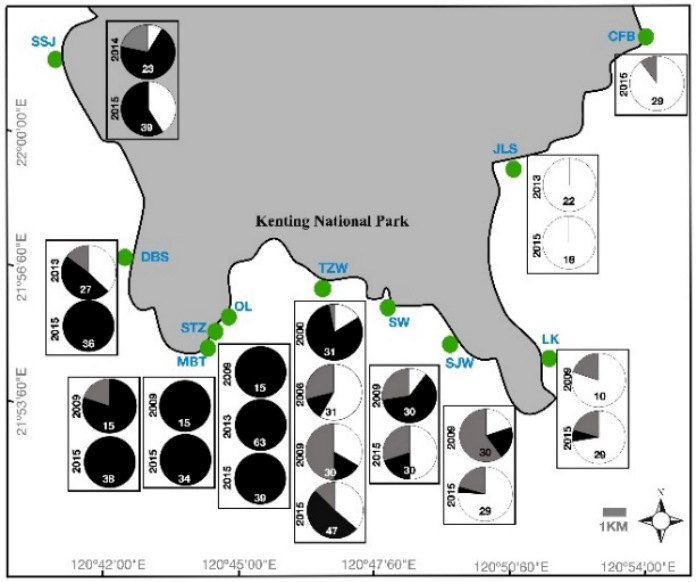




\section{Reference}

1. Keshavmurthy, S.; Kuo, C.-Y.; Huang, Y.-Y.; Carballo-Bolaños, R.; Meng, P.-J.; Wang, J.-T.; Chen, C.A. Coral Reef Resilience in Taiwan: Lessons from Long-Term Ecological Research on the Coral Reefs of Kenting National Park (Taiwan). J. Mar. Sci. Eng. 2019, 7, 388. [CrossRef]

Publisher's Note: MDPI stays neutral with regard to jurisdictional claims in published maps and institutional affiliations.

(C) 2020 by the authors. Licensee MDPI, Basel, Switzerland. This article is an open access article distributed under the terms and conditions of the Creative Commons Attribution (CC BY) license (http://creativecommons.org/licenses/by/4.0/). 